\title{
PRODUCT VARIETY IN CONSTRUCTION: A CRITICAL REVIEW AND WAY FORWARD
}

\author{
Cecilia Gravina da Rocha ${ }^{1}$ and Sergio Kemmer ${ }^{2}$
}

\begin{abstract}
This paper presents a critical analysis of current construction literature on product variety. In particular, two theoretical bases, namely, (i) hierarchical product breakdown and (ii) generic supply chain types, that address such conceptualization are reviewed. Three limitations were encountered, which hinder their application in measuring levels of product variety and associated disruptions in the production flow of building projects. Hierarchical product breakdowns (i) do not reflect the production sequence employed for erecting a building and (ii) do not enable spatial and layout changes (a key aspect of variety in building projects) to be appropriately framed. Supply chain types, in turn, provide only a high-level understanding of the effect of product variety (or customisation) on the production flow, and thus do not allow product variety to be assessed and compared at a project level. The paper concludes by discussing a number of conceptualizations (Work structure \& Work Packages, Product Variants, Decoupling Point, Modules, and Design Structure Matrix) that can advance in the understanding of product variety in construction.
\end{abstract}

\section{KEYWORDS}

Customization, process, flow, work packages, modularity.

\section{INTRODUCTION}

The Transformation-Flow-Value theory (TFV) emphasizes that construction should be viewed as (i) transformation of inputs into outputs, (ii) flow comprised of value-adding activities and non-value-adding activities (waste), and (iii) value generation (Koskela 2000). The flow view is relevant as it shines a spotlight on waste (Sacks 2016; Sacks et al. 2017): products wait for crews and crews wait for materials, information, equipment, space, to complete a task. Waste exists in construction due to inherent variability of processes (Hopp and Spearman 2001) and also due to specificities of this sector (e.g., Tommelein et al. 1999, Vrijhoef and Koskela 2000). Yet, it is aggravated when customization (or product variety) is offered.

Customization requires clients to provide an input, which usually consists of design drawings with changes in terms of layout and/or material specifications, for units forming a building (offices or apartments in a building, stores in a mall, etc.). Customization contributes to the value element of TFV by fulfilling clients' specific requirements. Yet, it introduces an additional source of variability in the production flow. Indeed,

1 Lecturer, School of Civil and Environmental Engineering, University of Technology Sydney (UTS), Australia. cecilia.rocha@uts.edu.au, orcid.org/0000-0001-6764-1724

2 Director, SK Consultoria e Treinamento, Curitiba - Parana, Brazil (https://www.sergiokemmer.com) contato@sergiokemmer.com, orcid.org/0000-0002-0803-2096 
customization creates different types of waste as exemplified in the project examined by Sacks and Goldin (2007) and Sacks et al. (2007), detailed as follows. Delays in receiving clients input lead to waiting for such input or to rework (in case a standard unit is already built). Such waiting is often fought back by working in several (or all) units, which creates inventory and excessive movement of crews and/or materials. Lastly, unnecessary activities such as cleaning and repairing are also required since units stay as work-inprogress for long periods.

Besides the variability in client input, customization also creates variability (or variety) of the product itself (da Rocha et al. 2016): namely, rather than having a single standard product for the units forming a building, each of these becomes a product variant. While the former source of variability and its effect on the production flow has been examined, the latter has not received the same attention. It is acknowledged that product variety negatively affects production. Increasing the number of product variants creates (Fisher and Ittner 1999): (i) less accurate demand forecasts, (ii) high levels of inventories and materials transportation, (ii) additional setups, (iii) a complex scheduling, (iv) increased supervision requirements, and (v) risk of workers selecting the wrong parts.

Yet, it is unclear how to measure product variety levels (or customisation levels) in construction as well as the extent of disruptions in the production flow yield by such different levels. Upon reviewing two theoretical bases for understanding such concept in this sector (i.e. hierarchical product breakdown and supply chain types), three limitations were encountered and are discussed here. In order to address such limitations, a number of conceptualizations from construction and manufacturing (Work structure \& Work Packages, Product Variants, Decoupling Point, Modules, and Design Structure Matrix) that can advance in the understanding of product variety in construction are reviewed.

\section{PRODUCT VARIETY IN CONSTRUCTION}

\section{Hierarchical Product Breakdown}

Open Building (Habraken 1972) introduced the notion of buildings being composed by two levels (infill and support). Yet, a detailed breakdown of buildings and their constitutive physical parts was only later proposed by Schoenwitz et al. (2012). Such a breakdown suggests that buildings can be organized in three hierarchical levels (Schoenwitz et al. 2012, 2017): categories, components, and sub-components (Figure 1). The criteria for such a breakdown are not clearly presented in the above-mentioned studies, but the results suggest they involve (i) the physical decomposition of a building (ii) from the highest to the lowest level (i.e. the entire building to individual components such as tiles or bricks).

The categories level seems to address a building systems as suggested by the terms "sanitary" and "heating" presented in Schoenwitz et al. (2012). Systems (structural, enclosure, electrical, heating, etc.) can indeed be decomposed into components and subcomponents. However, it is not clear what "construction design" and "internal design" (in Schoenwitz et al. 2012, 2017) might be in terms of systems. Particularly, it is puzzling to have "house" as a component of the "construction design" category in Schoenwitz et al. (2012). Similarly, "roof" (under "construction design") is formed by "tiles", "dormer", "windows" but also by "type" and "conversion" which do not seem to be sub-components.

Despite these problems, hierarchical product breakdown is in line with product architecture (e.g., Ulrich 1995, Fixson 2005) and the notion that a product can be subsequently decomposed or partitioned (both in terms of components and functions). 
Nonetheless, such partitioning, particularly in terms of components, should reflect the product assembly or manufacturing. For example, small components (metal plates, bolts, axis, etc.) are grouped into particular modules (box, hitch, fairing, bed, springs, and wheels) in the cargo trailer examined in Ulrich (1995) and Fixson (2005) because these are the chunks used for assembly. Likewise, a cockpit is defined as a module (from the car manufacturer perspective) since it is the chunk added in the car assembly line (Baldwin and Clark 2003).

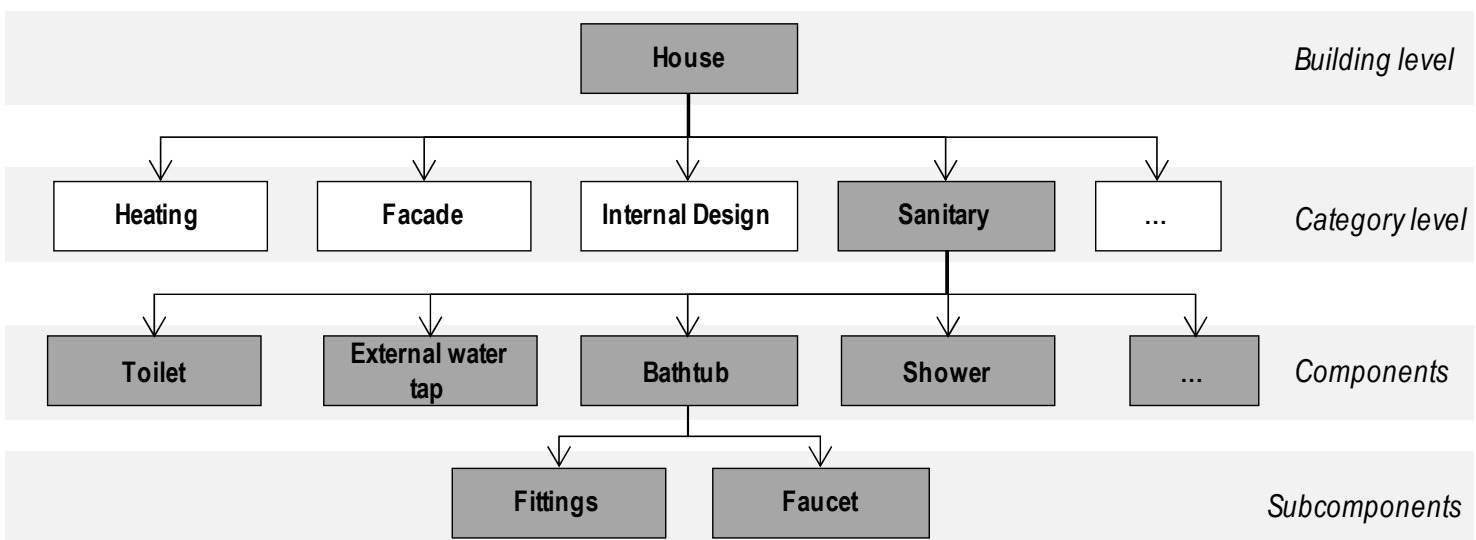

Figure 1 - Example of a hierarchical product breakdown (based on Schoenwitz et al. 2012, 2017)

\section{SuPPly Chain TyPes}

Hoekstra et al. (1992) suggest that customization and its impacts on operations can be determined by the Decoupling Point (DP). The DP is the first point in which a client order enters the supply chain, thus separating forecast and demand driven tasks (Naylor et al. 1999, Olhager 2003, Yang and Burns 2003, Yang et al. 2004). Five supply chain types emerge by varying the DP position (Hoekstra et al. 1992): make and ship to stock, make to stock, assemble to order, make to order, and purchase and make to order. These were later re-named and detailed (Naylor et al. 1999) as shown in the first and second columns of Table 1: buy to order (unique products), make to order (bespoke products made from the same materials), assemble to order (products made from a pre-defined mix of parts), make to stock (standard products delivered to varied locations), and ship to stock (standard products delivered to fixed locations).

Barlow et al. (2003) propose a one-to-one correspondence between the five supply chain types and customization strategies (Lampel and Mintzberg 1996): pure standardization, segmented standardization, customized standardization, tailored customization, and pure customization (a product designed according to clients order). They also convert the four generic production stages (Table 1) in a combination of (i) production stages (e.g., design, distribution, assembly) and (ii) physical parts (e.g., components, sub-assemblies) to adapt the supply chain types (Hoekstra et al. 1992, Naylor et al. 1999) to house building. More recently, Schoenwitz et al. (2017) used these supply chain types (Barlow et al. 2003) and the hierarchical product breakdown (Schoenwitz et al. 2012) to analyse the Decoupling Points (DPs) in building products. 
Table 1: Relationships: DP location, supply chain type, and customization strategy

\begin{tabular}{ccc}
\hline Generic production stage & Supply chain type & Customization strategy \\
\hline DP in design & Buy to order & Pure customization \\
DP in fabrication & Make to order & Tailored customization \\
DP in assembly & Assemble to order & Customized standardization \\
DP in distribution & Make to stock & Segmented standardization \\
-- & Ship to stock & Pure standardization \\
\hline
\end{tabular}

\section{LIMITATIONS OF CURRENT UNDERSTANDINGS}

Two limitations arise when using a hierarchical product breakdown as in Schoenwitz et al. $(2012,2017)$ for assessing variety in construction. First, such breakdown does not reflect how buildings are erected. Buildings are often produced by adding component and sub-components from different systems throughout the construction process rather than assembling only components and sub-components from a specific system and finally adding all systems together. Furthermore, the construction processes can vary from traditional construction (bricks and cast in place concrete) to full off-site construction (volumetric pods only assembled on-site). This differs from manufacturing in which a single set of modules and a unique process are used to deliver a large number of products.

The second limitation refers to spatial (or layout) changes such as integrating a bedroom space (by removing walls) to create a large living room. Such changes are a fundamental element of variety in buildings that cannot be appropriately framed in hierarchical product breakdowns. This is because such breakdowns are organized in terms of systems (and their constitutive physical parts such as components and sub-components) instead of spaces such as living room, kitchen, bedroom, etc. (and the physical parts enclosing such spaces that pertain to distinct systems). Yet, the latter (spaces) instead of the former (physical parts) is the appropriate unit for framing spatial (or layout) changes.

Lastly, the positioning of the DP in generic stages (or supply chain types) such as in Barlow et al. (2003) and Schoenwitz et al. (2017) allows only a generic understanding of customization (or product variety) and its implications in production. Indeed, it can be used to position and characterize construction in comparison to other sectors: construction is often labelled as engineer to order (e.g., Pero et al. 2015). However, this definition does not assist practitioners in defining customization strategies for the project at hand. This is because the operational impact of distinct variety levels embedded in such strategies (namely, attributes and options) is not clear.

\section{RELEVANT NOTIONS FOR UNDERSTANDING PRODUCT VARIETY IN CONSTRUCTION}

\section{Work Structure \& Work Packages}

Work structure refers to the packaging of tasks and related resources (crews, materials, design information, equipment) needed to erect a building into chunks or work packages (Ballard 1999; Tsao, 2005; Tsao et al., 2004). Managing such chunks (instead of individual tasks) reduces the number of hand-offs, thus simplifying production. Differently from manufacturing in which a single process (workstations in a factory) delivers a large number of products, each building is erected via a unique work structure (or process) (da Rocha and Kemmer 2018). Such one-off nature arises from specific 
characteristics that define construction: (i) temporary supply chains often put together to deliver only one project (Vrijhoef and Koskela 2000) and (ii) varied construction methods ranging from traditional bricks and blocks to volumetric pods fully produced off-site.

Work packages are considered here to be the output of work structuring (as defined by Ballard 1999), namely, the "chunks" in terms of production that need to be carried out to complete a building. A number of studies (e.g., Spitler and Wood 2016; Tsao et al. 2004) have detailed the elements comprising a work package. Here a work package is considered to involve (da Rocha and Kemmer 2018): (i) the resources to complete the construction tasks, (ii) the crew, and (iii) the construction tasks carried out. Such resources are understood here as the pre-requisite conditions for task completion defined by Koskela (2000): construction design; components, and materials; workers; equipment; space, connecting works; and external conditions.

\section{Product VARiants}

Product variety arises from a set of attributes for which different options (or levels) are offered. Each attribute can be specified at distinct options, yet only one option is activated at each product variant (Raman 1995). Thus, the amount of product variants is a function of the number of customizable attributes and options. In case all attributes are independent and all options can be combined, the amount of product variants is straightforward: the product (multiplication) of all options offered. Scavarda et al. (2010) propose a similar formula for cars involving the amount of (i) car models, (ii) body style, (iii) powertrain, (iv) paint and trim combination, and (iv) factory fitted options (e.g., sunroofs, radio). Yet, some options are not available for all models (e.g., a sunroof for a convertible) and option bundling might also apply (e.g., fog lamps only on the winter package) (Scavarda et al. 2010; Pil and Holweg 2004), and thus need to excluded from the total amount of product variants (e.g., Stäblein et al. 2011; Scavarda et al. 2010). The amount of product variants might appeal as a/the measure of product variety due to its simplicity but it is not sufficient (e.g., Martin and Ishii 1996, Stäblein et al. 2011). Ten fundamentally different options (e.g., platforms) do not create the same variety level as ten similar options (e.g., colours) (Stäblein et al. 2011).

\section{Decoupling Point \& Postponement}

The Decoupling Point (DP) is the point in which client order enter the production or the supply chain. Its positioning in distinct generic stages such as fabrication, assembly, distribution, etc. has led to traditional supply chain types such as assemble-to-order, make-to-order and engineer-to-order (e.g., Hoekstra et al. 1992; Naylor et al. 1999) that illustrate the trade-off production efficiency and customisation. Indeed, as the DP moves upstream the product variety (or customisation) levels increases so does the operational impact, resulting in high costs and delivery time (Olhager 2003). Barlow et al. (2003) adapted such generic supply chain to the construction context and more recently Rocha and Kemmer (2013) proposed the use of DP in the context of work packages and line of balance. That is, the DP would be located in the first work package for which client input is needed to perform the construction tasks.

Postponement is closely related to the Decoupling Point (DP) and the ensuing supply chain types. Such concept seeks to minimize the uncertainty and variability of the logistics and manufacturing operations affected by client input (or customisation requirements) by postponing such activities as much as possible (Pagh and Cooper 1998). Similar to the supply chain types, different postponement strategies can be applied such 
as (i) labelling postponement, (ii) packaging postponement, (iii) assembly postponement, (iv) manufacturing postponement, and (v) time postponement (Zinn and Bowersox 1998). This same rationale has been explored in construction by Rocha and Kemmer (2013), which proposed and simulated the implementation of Delayed Production Differentiation (a synonymous for postponement) for an apartment building project.

\section{MODULES}

Previous studies (Gosling et al. 2016; da Rocha and Kemmer 2018) have shown that modules can assume distinct forms in construction projects ranging from simple and small components (e.g., brick, rebars, pipe) to large and complex sub-assembly (e.g., prefabricated pods). In addition, they can be understood from a spatial or componentoriented perspective (Rocha et al. 2015) both of which involve the definition of functional elements, physical components, and interfaces as discussed by Ulrich (1995). The former focuses on the activities performed by people in the spatial voids such as working, cooking, reading, sleeping. The latter focuses on the functions (e.g., thermal insulation, load bearing, etc.) performed by the physical mass forming a building such as beams, walls, ceiling, etc. (Rocha et al. 2015, Rocha and Koskela 2020). Clearly, adopting a spatial perspective requires the components to be considered since spaces only exist in juxtaposition to physical mass. However, adopting a component-perspective creates the modularization of only a particular system (e.g., MEP system) rather than the building as whole, thus limiting the benefits created (Rocha and Koskela 2020).

\section{Design STRUCTURe MATRIX (DSM)}

Design Structure Matrix (DSM) is a tool used to model systems, in particular their decomposition into parts (or subsystems) and their integration (Tuholski and Tommelein 2008). It enables the relationship between such subsystems as well as internal and external inputs and their impact on the system to be noted (Browning 2001). DMS modelling entail three basis steps (Tuholski and Tommelein 2008): (1) decomposition of a system or process into discrete parts, identifying inputs, outputs and information dependencies; (2) organization of such parts in a matrix with identical rows and columns and marking of connections between rows and columns; and (3) triangulation, entailing the identification of dependencies among parts (such as parallel, sequential, or coupled). Browning (2001) classifies DSMs in two major groups: (i) static, which represents parts coexisting at the same moment in time such as components of a product architecture or members in an organization and (ii) time-based, which models events over time such as activities that are carried out to complete a project.

In construction, many studies appear to fall on the second group as they map the relationships among the activities involved in projects design or construction (e.g., Khalife et al. 2018; Rosas 2013; Tuholski and Tommelein 2008). Differently, the theme of product variety appears to bridge the static and the time-based domains. The former is related to the modelling of modules and platforms and the connections among them (similar to Veenstra et al. 2006). DSM could be applied to identify such parts (based on step 1) and the relationships among them (based on step 2 and 3), defining more or less coupled interfaces. The latter is related to the construction activities required to complete a project and the relationships among them, thus similar to previous studies on DSM in construction. The final step would require these two matrices (static modelling of product architecture and time-based modelling of work packages) to be integrated: by identifying when the modules and platform are assembled or erected within the work packages as 
well as the critical points in construction (interfaces between such parts identified in the first matrix).

\section{DISCUSSION}

Work Structure \& Work packages and Design Structure Matrix (DSM) seem to provide suitable theoretical basis to model the product and process perspectives required to understand product variety in construction. Both appear to be sufficiently generic and flexible to accommodate distinct production sequences and construction methods used. The other conceptualizations account for the effect of distinct product variety levels in the production. Overall, disruptions in flow arising from product variety augments as (i) the number of product variants increases, (ii) the number of work packages delivering product variants rather than a single standard product increases, (iii) the DP moves to an upstream position, and (iv) the number of modules in work packages increases. This last notion exacerbates the 'matching problem' (Tommelein 2006), which shows that as the number of different units (e.g., pipe spools) increases, the time needed for matching each of them to their correct position/locations augments substantially. The reasoning behind all these trends (except for the DP) is based on the notion that complexity increases as the number of parts increases (Baccarini 1996) or conversely that simplification is achieved by reducing the number of parts (Koskela 2000).

This seems particularly appropriate considering the labour-intensive nature of construction and that having more parts or elements to cope with increases the cognitive burden and consequently the potential for errors and reworks, which directly affect flow. Furthermore, construction is most often characterized by a sequential configuration also known as the Parade of Trades (Tommelein et al. 1999). Thus, any disruptions in early work packages affect not only affect such work package but potentially all subsequent ones. As a result, the potential for disruptions in the production flow reduces, as the delivery of product variants (marked by the work package in which the DP is located) is postponed. Finally, although work packages, which map the construction activities, provide the focal point here for analysing disruptions in flow yield by product variety, such impact are determined to a large extent by design decisions. For example, layout options might be devised in a way to minimize changes in walls that have MEP embedded (or alternatively to have such systems embedded in other walls) to reduce the number of work packages impacted by customisation.

\section{CONCLUSIONS}

This paper performed a critical analysis of two main conceptual frameworks (hierarchical product breakdowns and supply chain types) addressing product variety (or customisation) in construction. Three limitations were encountered mainly related to specificities of construction not being appropriately framed or considered in such frameworks (e.g., spatial or layout aspects of product variety and the varied production sequences and methods employed for erecting buildings). This in turn hinders their usage to assess the product variety at a project level and precludes a detailed assessment of the disruptions in the production flow created by distinct product variety levels. It also suggests that new conceptual frameworks that allow the granularity and data at a project level are needed.

Seeking to address this problem, a number of conceptualizations from construction and manufacturing domains were reviewed: Work Structure \& Work Packages, Product Variants, Decoupling Point (DP), Modules, and Design Structure Matrix (DSM). In this 
sense, Work Structure \& Work Packages and Design Structure Matrix (DSM) emerge as a promising theoretical bases for understanding product variety and applying conceptualizations such as Product Variants, Decoupling Point (DP), and Modules to assess the extent of disruptions in flow crated by distinct levels of product variety. Clearly, this study and propositions have an exploratory nature and should be integrated in a cohesive framework to be applied in real world projects.

\section{ACKNOWLEDGMENTS}

The authors would like to thank the anonymous reviewers for their comments and feedback, which have greatly improved the breadth of relevant conceptualizations for product variety reviewed and discussed in this manuscript.

\section{REFERENCES}

Baccarini, D. (1996). "The concept of project complexity-a review." International Journal of Project Management, 14(4), 201-204.

Baldwin, C. Y., and Clark, K. B. (2003). "Managing in an age of modularity." Managing in the modular age: Architectures, networks, and organizations, 149, 84-93.

Ballard, G. (1999). "Work structuring." White Paper, 5.

Barlow, J., Childerhouse, P., Gann, D., Hong-Minh, S., Naim, M., and Ozaki, R. (2003). "Choice and delivery in housebuilding: lessons from Japan for UK housebuilders." Building Research \& Information, 31(2), 134-145.

Browning, T. R. (2001). "Applying the design structure matrix to system decomposition and integration problems: a review and new directions." IEEE Transactions on Engineering Management, 48(3), 292-306.

Fisher, M. L., and Ittner, C. D. (1999). "The Impact of Product Variety on Automobile Assembly Operations: Empirical Evidence and Simulation Analysis." Management Science, 45(6), 771-786.

Fixson, S. K. (2005). "Product architecture assessment: a tool to link product, process, and supply chain design decisions." Journal of Operations Management, 23(3-4), 345-369.

Gosling, J., Pero, M., Schoenwitz, M., Towill, D., and Cigolini, R. (2016). "Defining and Categorizing Modules in Building Projects: An International Perspective." Journal of Construction Engineering and Management, 142(11), 04016062.

Habraken, N. J. (1972). Supports: an alternative to mass housing. Architectural Pr, London.

Hoekstra, S., Romme, J., and Argelo, S. M. (Eds.). (1992). Integral logistic structures: developing customer-oriented goods flow. Industrial Press, New York.

Hopp, W. J., and Spearman, M. L. (2001). Factory physics: foundations of manufacturing management. Irwin/McGraw-Hill, Boston.

Khalife, S., Mneymneh, B. E., Tawbe, A., Chatila, M. H., and Hamzeh, F. (2018). "Employing Simulation to Study the Role of Design Structure Matrix in Reducing Waste in Design." 26th Annual Conference of the International Group for Lean Construction, Chennai, India, 879-889.

Koskela, L. (2000). An exploration towards a production theory and its application to construction. VTT Technical Research Centre of Finland.

Lampel, J., and Mintzberg, H. (1996). “Customizing customization.” Sloan management review, 38(1), 21. 
Martin, M. V., and Ishii, K. (1996). "Design for variety: a methodology for understanding the costs of product proliferation." Proceedings of The 1996 ASME Design Engineering Technical Conferences and Computers in Engineering Conference, California.

Naylor, J. B., Naim, M. M., and Berry, D. (1999). "Leagility: Integrating the lean and agile manufacturing paradigms in the total supply chain." International Journal of Production Economics, 62(1-2), 107-118.

Olhager, J. (2003). "Strategic positioning of the order penetration point." International Journal of Production Economics, 85(3), 319-329.

Pagh, J. D., and Cooper, M. C. (1998). "Supply chain postponement and speculation strategies: How to choose the right strategy." Journal of business logistics, Blackwell Publishing Ltd, Hoboken, 19(2), 13.

Pero, M., Stößlein, M., and Cigolini, R. (2015). "Linking product modularity to supply chain integration in the construction and shipbuilding industries." International Journal of Production Economics, 170, 602-615.

Pil, F. K., and Holweg, M. (2004). "Linking Product Variety to Order-Fulfillment Strategies." Interfaces, 34(5), 394-403.

Raman, N. (1995). "Simultaneous determination of product attributes and prices, and production processes in product-line design." Journal of Operations Management, 12(3-4), 187-204.

da Rocha, C. G., and Kemmer, S. (2018). "Integrating product and process design in construction." Construction Management and Economics, 36(9), 535-543.

da Rocha, C. G., Kemmer, S. L., and Meneses, L. (2016). "Managing Customization Strategies to Reduce Workflow Variations in House Building Projects." Journal of Construction Engineering and Management, 142(8), 05016005.

Rocha, C. G. da, and Koskela, L. (2020). "Why Is Product Modularity Underdeveloped in Construction?" Proc. 28th Annual Conference of the International Group for Lean Construction (IGLC), Berkeley, California, USA, 697-708.

Rosas, E. (2013). "Integrating the Design Structure Matrix and the Last Planner System Into Building Design." 21 th Annual Conference of the International Group for Lean Construction, C. T. Formoso and P. Tzortzopoulos, eds., Fortaleza, Brazil, 389-398.

Sacks, R. (2016). "What constitutes good production flow in construction?" Construction Management and Economics, 34(9), 641-656.

Sacks, R., Esquenazi, A., and Goldin, M. (2007). "LEAPCON: Simulation of Lean Construction of High-Rise Apartment Buildings." Journal of Construction Engineering and Management, 133(7), 529-539.

Sacks, R., and Goldin, M. (2007). "Lean Management Model for Construction of HighRise Apartment Buildings." Journal of Construction Engineering and Management, 133(5), 374-384.

Sacks, R., Seppänen, O., Priven, V., and Savosnick, J. (2017). "Construction flow index: a metric of production flow quality in construction." Construction Management and Economics, 35(1-2), 45-63.

Scavarda, L. F., Reichhart, A., Hamacher, S., and Holweg, M. (2010). "Managing product variety in emerging markets." International Journal of Operations \& Production Management, 30(2), 205-224.

Schoenwitz, M., Naim, M., and Potter, A. (2012). "The nature of choice in mass customized house building." Construction Management and Economics, 30(3), 203219. 
Spitler, L., and Wood, N. (2016). "Work Structuring at the Boundary of Realization: A Case Study Analysis." 24th Annual Conference of the International Group for Lean Construction, Boston, USA.

Stäblein, T., Holweg, M., and Miemczyk, J. (2011). "Theoretical versus actual product variety: how much customisation do customers really demand?" International Journal of Operations \& Production Management, (P. Jonsson, ed.), 31(3), 350-370.

Tommelein, I. D. (2006). "Process Benefits From Use of Standard Products - Simulation Experiments Using the Pipe Spool Model." 14th Annual Conference of the International Group for Lean Construction, Santiago, Chile, 177-188.

Tommelein, I. D., Riley, D. R., and Howell, G. A. (1999). "Parade Game: Impact of Work Flow Variability on Trade Performance." Journal of Construction Engineering and Management, 125(5), 304-310.

Tsao, C. C. Y. (2005). "Use of Work Structuring to Increase Performance of ProjectBased Production Systems." University of California Berkeley, Berkeley.

Tsao, C. C. Y., Tommelein, I. D., Swanlund, E. S., and Howell, G. A. (2004). "Work Structuring to Achieve Integrated Product-Process Design." Journal of Construction Engineering and Management, 130(6), 780-789.

Tuholski, S. J., and Tommelein, I. D. (2008). "Design Structure Matrix (DSM) Implementation on a Seismic Retrofit." 16th Annual Conference of the International Group for Lean Construction, P. Tzortzopoulos and M. Kagioglou, eds., Manchester, UK, 471-484.

Ulrich, K. (1995). "The role of product architecture in the manufacturing firm." Research Policy, 24(3), 419-440.

Veenstra, V. S., Halman, J. I. M., and Voordijk, J. T. (2006). "A methodology for developing product platforms in the specific setting of the housebuilding industry." Research in Engineering Design, 17(3), 157-173.

Vrijhoef, R., and Koskela, L. (2000a). "The four roles of supply chain management in construction." European Journal of Purchasing \& Supply Management, 6(3-4), 169178.

Vrijhoef, R., and Koskela, L. (2000b). "The four roles of supply chain management in construction.” European Journal of Purchasing \& Supply Management, 6(3-4), 169178.

Yang, B., and Burns, N. (2003). "Implications of postponement for the supply chain." International Journal of Production Research, 41(9), 2075-2090.

Yang, B., Burns, N. D., and Backhouse, C. J. (2004). "Postponement: a review and an integrated framework." International Journal of Operations \& Production Management, 24(5), 468-487.

Zinn, W., and Bowersox, D. J. (1998). "Planning Physical Distribution with the Principle of Postponement." Journal of Business Logistics, 9(2), 117-136. 